SHORT REPORT

\title{
Prevalence of severe fatigue in primary care
}

\section{C Haines, G Saidi, R W I Cooke}

Arch Dis Child 2005;90:367-368. doi: 10.1136/adc.2003.039917

A postal survey of 1024 UK GP practices showed the prevalence of medically unexplained severe fatigue over three months in 5-19 year olds to be $62 / 100000$. Cases were predominantly adolescent girls and were more likely to come from practices in less deprived areas, which could reflect consulting behaviours.

A lthough chronic fatigue in UK adult primary care patients is relatively common, ${ }^{1}$ there have been no comparative studies in children. Estimates of the prevalence of chronic fatigue syndrome (CFS) or CFS-like illness in children vary widely according to case definition and methodology and range from 2.7/100 $000^{2}$ to 570/ $100000,{ }^{3}$ although they all suggest that the prevalence is lower than among adults. ${ }^{1}$

The diagnosis of CFS is one of exclusion. Although there are internationally accepted diagnostic criteria for CFS in adults, ${ }^{4}$ there are none for children. Most studies have applied adult criteria, although it has been suggested that three rather than six months of fatigue is more appropriate for children. ${ }^{5}$ There is also evidence from adult studies that CFS-like illnesses are given a variety of diagnostic labels by GPs. ${ }^{16}$ Given these considerations, estimating the prevalence of CFS-like illness in the primary care population requires a broad case definition in the absence of independent medical assessment. This paper reports a survey of cases of severe disabling fatigue of over three months in 5-19 year olds in primary care and the diagnoses given by the GP.

\section{METHODOLOGY}

In 2000 a postal survey of the 1024 practices in the MRC's General Practice Research Framework (GPRF) was undertaken. Nurses reported the number of 5-19 year olds consulting their GP in 1999 with severe disabling fatigue for at least three months with a premorbid level of activity significantly reduced or impaired, including patients who had subsequently recovered. For each case, we obtained age, sex, GPs' provisional diagnosis, the practice's 5-19 year old population, and Jarman deprivation score. No patient identifiers were collected and practices remained anonymous to the researchers; ethical approval was not sought.

\section{RESULTS}

A total of 718 practices $(70 \%)$ responded, reporting 542 patients; 444 practices had none and 274 had at least one; median number of cases per practice was 1 (range 1-17).

Age and sex were provided for 480 cases (88\%) (fig 1); 316 were girls (66\%) and the proportion increased with age: $50 \%$ $(12 / 24)$ of 5-9 year olds, $62 \%$ (147/236) of 10-15 year olds, and $72 \%(155 / 214)$ of $16-19$ year olds. The peak of cases was at 15 years of age $(n=78)$; in boys the number of older cases dropped sharply, whereas in girls the number remained high until 18.
A clinical member of the research team (RWIC) reviewed 468 cases $(86 \%)$ with known diagnosis to identify cases where medical or psychiatric diagnoses (other than CFS/ME) might explain the fatigue. ${ }^{4}$ In 13 cases $(2.7 \%)$ the diagnosis provided a likely medical explanation for the fatigue. In the remaining 455 cases it did not. These cases were grouped as: fatigue diagnoses $(n=281 ; 62 \%)$ (chronic fatigue (CF), CFS, fatigue/severe fatigue syndrome, fatigue, lethargy, malaise, $\mathrm{ME}$, CFS/ME, fibromyalgic CFS, and fibromyalgia); viral diagnoses (viral infection, post-viral fatigue) $(\mathrm{n}=154 ; 34 \%)$; and psychosocial diagnoses (depression, bullying, family factors) $(\mathrm{n}=20 ; 4 \%)$ (fig 2). Overall 234 cases $(51 \%)$ were diagnosed with CFS, ME, CF, or severe fatigue syndrome.

Prevalence was calculated using the 5-19 year old population given by 496 practices. Practices reporting over six cases with no diagnosis were excluded from the denominator. Excluding cases with diagnoses explaining the fatigue and those with no diagnosis, there were 410 cases in a population of 655668 , a prevalence of medically unexplained fatigue of $0.062 \%$ (95\% CI 0.056 to 0.069 ).

In 341 of these cases we have age information: $18(5 \%)$ were 5-9 years old, 88 (26\%) were $10-14$ years old, and 235 (69\%) 15-19 years old.

There was no difference in deprivation scores among responding and non-responding practices $(\mathrm{z}=-0.604$; $\mathrm{p}=0.546$; NS), but responders had a lower total practice population than non-responders $(\mathrm{z}=-2.68 ; \mathrm{p}=0.007)$ $($ median $=6500 \quad(\mathrm{IQR}=4005-10 \quad 108) \quad v \quad$ median $=7501$ $(\mathrm{IQR}=4450-11200))$.

Comparison of practices with and without cases showed those with cases had a higher total practice population $(\mathrm{z}=-6.640 ; \quad \mathrm{p}<0.001) \quad($ median $=8381 \quad(\mathrm{IQR}=5000-$ $11475) v$ median $=5740(\mathrm{IQR}=3500-8800))$ and were more likely to be in less deprived areas than those without cases $(\mathrm{z}=-3.977 ; \mathrm{p}<0.001) \quad($ median $=4(\mathrm{IQR}=-7$ to 13$) v$ median $=8(\mathrm{IQR}=-1$ to 19$))$.

\section{DISCUSSION}

This study was a retrospective cross-sectional survey with no validation of the diagnostic information given or clinical assessment of cases and a broad case definition. The cases nevertheless had similar characteristics to cases of childhood CFS previously described, with a predominance of girls and peak prevalence in adolescence. ${ }^{7}$ A recent adult primary care study suggests only one third of patients with over six months of fatigue met the CDC CFS criteria, ${ }^{6}$ and although over half of our sample were given fatigue diagnoses, it is likely that only some are cases of CFS if validated against established criteria. The prevalence of medically unexplained severe fatigue of over three months in 5-19 year olds in primary care of $62 / 100000$ is likely to be an underestimate, as smaller practices with fewer cases were more likely to participate, but nevertheless is similar to school surveys reporting $70 / 100000^{8}$ and health professional reported

Abbreviations: $\mathrm{CF}$, chronic fatigue; $\mathrm{CFS}$, chronic fatigue syndrome; $M E$, myalgic encephalomyelitis 


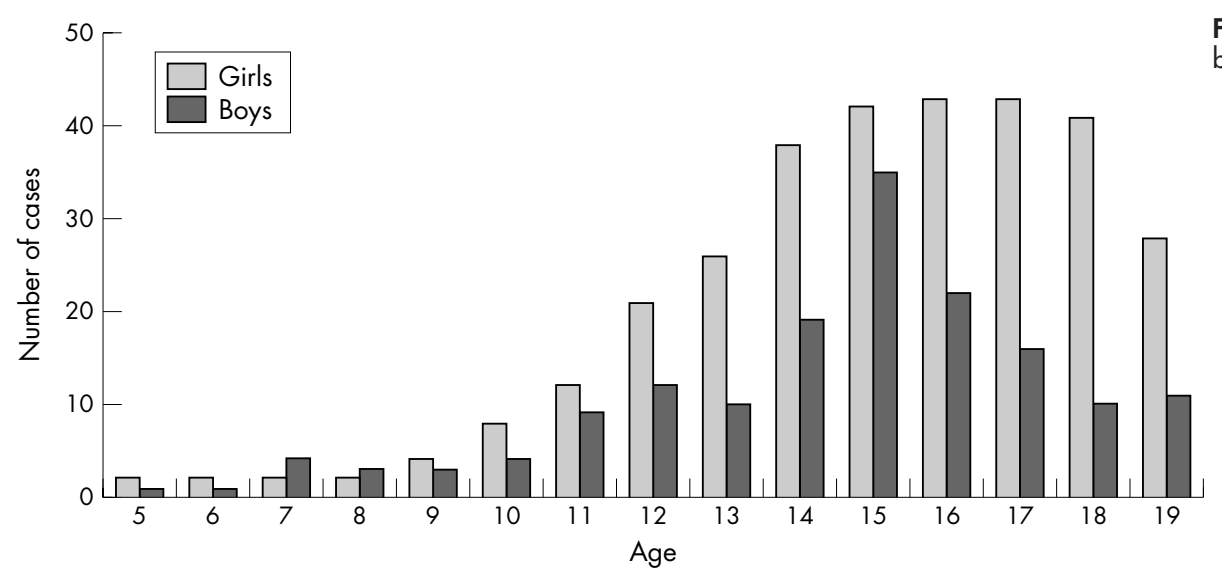

Figure 1 Breakdown of reported cases by age and gender $(n=474)$.

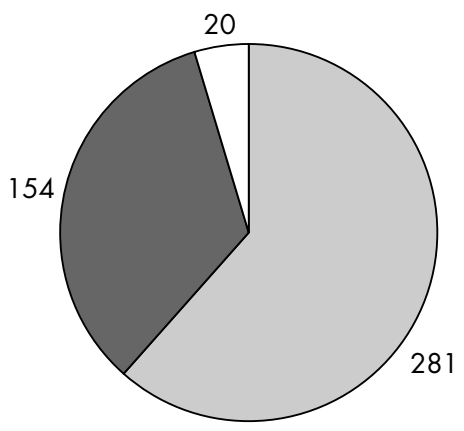

Fatigue diagnoses

Viral diagnoses

Psychosocial diagnoses

Figure 2 Provisional diagnoses given by GP $(n=455)$.

studies $^{9}$ reporting 47.9/100 000, but substantially lower than self-reported community surveys reporting 570/100 $000 .^{3}$

The association of cases with practices in less deprived areas could reflect differing underlying prevalence rates, but might also indicate a difference in consulting behaviour.

\section{ACKNOWLEDGEMENTS}

The authors wish to thank Dr Madge Vickers, Jeanette Martin, and Nicola Fasey of the GPRF for their support and assistance with this study as well as all the practice nurses participating in the survey.

\section{Authors' affiliations}

L C Haines, G Saidi, Royal College of Paediatrics and Child Health, London, UK

R W I Cooke, Liverpool Women's Hospital, UK
Funding: the research was funded by a grant from the Community Fund Competing interests: none declared

Correspondence to: Mrs L Haines, Principal Research Officer, Royal College of Paediatrics and Child Health, 50 Hallam Street, London WIW 6DE, UK; Linda.haines@rcpch.ac.uk

Accepted 24 September 2004

\section{REFERENCES}

1 Wessley S, Chalder T, Hirsch S, et al. The prevalence and morbidity of chronic fatigue and chronic fatigue syndrome: a prospective primary care study. Am J Public Health 1997;87:1449-55.

2 Dobbins JG, Randall B, Reyes M, et al. The prevalence of chronic fatiguing illnesses among adolescents in the United States. Journal of Chronic Fatigue Syndrome 1997;3(2):15-27.

3 Chalder T, Goodman R, Wessely S, et al. Epidemiology of chronic fatigue syndrome and self reported myalgic encephalomyelitis in 5-15 year olds: cross sectional study. BMJ 2003;327:654-5.

4 Sharpe MC, Archard LC, Banatvala JE, et al. A report-chronic fatigue syndrome: guidelines for research. J $R$ Soc Med 1991;84:1 18-21.

5 Royal College of Physicians. Report of a Committee of the Royal Colleges of Physicians, Psychiatrists and General Practitioners. Chronic fatigue syndrome. London: Royal College of Physicians, 1996.

6 Darbishire L, Ridsdale L, Seed PT. Distinguishing patients with chronic fatigue from those with chronic fatigue syndrome: a diagnostic study in UK primary care. Br J Gen Pract 2003;53:441-5.

7 Bell DS, Jordan K, Robinson M. Thirteen-year follow-up of children and adolescents with chronic fatigue syndrome. Pediatrics 2001;107:994-8

8 Dowsett EG, Colby J. Long-term sickness absence due to ME/CFS in UK schools: an epidemiological study with medical and educational implications. Journal of Chronic Fatique Syndrome 1997;3(2):29-47.

9 Lloyd AR, Hickie I, Boughton CR, et al. Prevalence of chronic fatigue syndrome in an Australian population. Med J Aust 1990;153:522-8. 